\title{
Molecular identification of Campylobacter jejuni and coli from chicken, calves and dogs to determine its potential threat on human being
}

\author{
Sonuwara Begum ${ }^{1}$, M. Sekar ${ }^{1}$, L. Gunaseelan², Monica Gawande ${ }^{1}$, G. Suganya ${ }^{1}$, P. Annal Selva Malar ${ }^{1}$ and A.Karthikeyan $^{1}$
}

1. Department of Veterinary Public Health and Epidemiology, Madras Veterinary College, Chennai, Tamil Nadu, India;

2. Dean, Veterinary College and Research Institute, Namakkal, Tamil Nadu Veterinary and Animal Sciences University, Chennai, Tamil Nadu, India.

Corresponding author: Sonuwara Begum, e-mail: Sonuwarabegum@yahoo.com, MS: muthu-sekar@yahoo.com, LG: Igseelan@yahoo.co.in, MG: drmonicagawande@gmail.com, GS: suganyamvc06@gmail.com, PASM: drannalselvamalar@gmail.com, AK: drkarthikeyanvet@gmail.com Received: 10-08-2015, Revised: 02-11-2015, Accepted: 09-11-2015, Published online: 18-12-2015

doi: 10.14202/vetworld.2015.1420-1423 How to cite this article: Begum S, Sekar M, Gunaseelan L, Gawande M, Suganya G, Malar PAS, Karthikeyan A (2015) Molecular identification of Campylobacter jejuni and coli from chicken, calves and dogs to determine its potential threat on human being, Veterinary World 8(12): 1420-1423.

\begin{abstract}
Aim: Campylobacter is an emerging zoonotic pathogen and one of the leading cause of foodborne infection worldwide and it has been isolated from a variety of animal species. The aim of this study was to identify Campylobacter jejuni and Campylobacter coli from dogs, calves, and poultry using polymerase chain reaction (PCR).
\end{abstract}

Methodology: A total of 104 number of samples comprising cloacal swab from poultry (38), a rectal swab from dogs (40), and calves (26) were collected for the isolation of thermophilic Campylobacters using conventional culture method. PCR was used for identification of mapA gene for C.jejuni and ceuE for C.coli.

Results: The overall presence of Campylobacter was found to be 67(64.42\%) from the samples, out of which 6 isolates belongs to $C$. jejuni species, were $5(18.51 \%)$ from chicken and $1(4.17 \%)$ from dog was recorded and about 17 isolates belongs to $C$. coli species were $9(33.33 \%), 6(25 \%)$, and 1(9.09\%) from chicken, dog and calves was recorded.

Conclusion: Results suggested that Campylobacter reservoirs chicken, calves and pet dogs can play a role as the source of infection to human beings and PCR can be an ideal tool for molecular confirmation at the species level.

Keywords: emerging, pathogen, thermophilic Campylobacter, zoonotic.

\section{Introduction}

The word "Campylobacter" is derived from the Greek word which denotes to its morphological shape which is curved rod, spiral or " $\mathrm{S}$ " shaped morphology under the microscope. The thermophilic Campylobacter spp. like Campylobacter jejuni, Campylobacter coli, Campylobacter lari, and Campylobacter upsalensis are able to grow at $42-43^{\circ} \mathrm{C}$ under microaerophilic conditions $\left(5 \% \mathrm{O}_{2}, 10 \% \mathrm{CO}_{2}\right.$, and $85 \% \mathrm{~N}_{2}$ ).

Campylobacter is one of the leading causes of foodborne diarrheal illness worldwide [1,2]. It is one of the emerging zoonotic pathogen and is responsible for more gastroenteritis cases than any other reported bacterial species in many countries [3].

Natural reservoirs of the bacteria are the gastrointestinal tract of farm and wild animals. Direct contact with carrier's animals is found to be a possible source of infection [4]. It is frequently isolated from a variety of animal species such as poultry, cattle, pigs, sheep, pets, wild birds, and rodents [5]. It was reported that about $70.9 \%$ of the human cases were attributed to chickens, $19.3 \%$ to cattle and $8.6 \%$ to dogs [6]. Handling or consumption of undercooked or contaminated

Copyright: The authors. This article is an open access article licensed under the terms of the Creative Commons Attributin License (http:// creative commons.org/licenses/by/2.0) which permits unrestricted use, distribution and reproduction in any medium, provided the work is properly cited. meat is considered as the significant source of human Campylobacter spp. infection but also other risk factors responsible for its transmission are ingestion of contaminated dairy products, water, foreign travel, and swimming in natural sources of water [7]. Large outbreaks of campylobacteriosis are rare as most cases of human illness appear to be sporadic. Difficulties in identifying the source of sporadic infections are compounded due to the widespread occurrence of these pathogens in the environment $[8,9]$.

Molecular methods have facilitated the development of nucleic acid-based detection methods which are more rapid, sensitive and specific. Polymerase chain reaction (PCR) has been used for diagnosis which has proven to be a fast, highly discriminative and relatively simple method [10]. Virulence factors in C.jejuni and C.coli are a useful tool to assess the potential risk of poultry as a source of Campylobacter infection [11]. Adopting the specific gene target in routine diagnosis will help in the improved understanding of the prevalence and the epidemiology of this emerging infection.

\section{Materials and Methods}

\section{Ethical approval}

Prior consent of the owners was taken before collection of a rectal swab from dogs, calves and cloacal swabs from chicken. Proper ethical considerations related to handling and not to cause any injury during sampling was taken. 


\section{Collection of samples}

A total of 104 number of samples comprising cloacal swab from poultry (38), the rectal swab from dogs (40), and calves (26). The samples were collected from Department of Clinics and Post-graduate Research Institute of Animal science, Kattupakam using sterile cotton swabs (Himedia, India) and transported in an icebox to a laboratory for processing and microbiological analysis.

\section{Processing of samples}

The samples were collected by using sterile cotton swabs (Himedia, India) and brought immediately to the laboratory for processing. The samples were put in Blood free Campylobacter broth base (M1318, HiMedia Pvt. Ltd., Mumbai, India) with Campylobacter growth supplement (HiMedia Pvt. Ltd., Mumbai, India) and incubated under microaerophilic conditions at $42^{\circ} \mathrm{C}$ for $24 \mathrm{~h}$. A loopful of inoculum from broth was streaked into blood free Campylobacter selectivity agar base (M887, HiMedia Pvt. Ltd., Mumbai, India) plates and incubated for $48 \mathrm{~h}$ at $42^{\circ} \mathrm{C}$ under micro-aerophilic conditions by using internal gas generation system. This was accomplished by using equal quantity of citric acid, sodium bicarbonate and sodium borohydride which fills the jar environment with $85 \% \mathrm{~N}_{2}, 10 \% \mathrm{CO}_{2}$, and $5 \% \mathrm{O}_{2}$ [12].

\section{Molecular confirmation by PCR Extraction of DNA}

Grey color, spreading type colonies with sticky nature were suspected for Campylobacter. Based on colony morphology suspected colonies were picked up. The DNA of Campylobacter spp. isolates was prepared by taking loopful of $48 \mathrm{~h}$ test culture in $100 \mu \mathrm{l}$ of sterilized DNAse and RNAse free milliQ water in micro centrifuge. The samples were vortexed and heated at $95^{\circ} \mathrm{C}$ for $10 \mathrm{~min}$, cell debris was removed by centrifugation, and $3 \mu 1$ of the supernatant was used as a DNA template in PCR reaction mixture.

\section{Oligonucleotide primers}

Stock solutions of the primers were made in nuclease-free water and stored at $-20^{\circ} \mathrm{C}$. The working solutions were made to $10 \mathrm{pmol} / \mu \mathrm{l}$ after suitable dilution. The isolates were identified at genus level by PCR targeting the mapA and ceuE gene of Genus Campylobacter. The primer used in the present study is taken from already published article [10] and the details of the primer pair used are given in (Table-1). All PCR amplifications were performed in a mixture $(25 \mu \mathrm{l})$ containing nuclease free water, primers, Taq polymerase, and template DNA. The amplification was carried out in a thermal cycler with the following cycling conditions as shown in (Table-2).

\section{Results}

\section{Prevalence of Campylobacter}

In the present study, the overall prevalence of Campylobacter was found to be 67 (64.42\%) from the samples based on colony morphology and microscopic
Table-1: Sequence of primers used in PCR for $C$. jejuni and C. coli.

\begin{tabular}{llc}
\hline Primer name & Sequence & Product size \\
\hline MDmapA1FP & 5'-CTA TTT TAT TTT & 589 bp \\
& TGA GTG CTT GTG-3' & \\
MDmapA2RP & 5'-GCT TTA TTT GCC & \\
& ATT TGT TTT ATT A-3' & \\
COL3 F & 5'-AAT TGA AAA TTG & $462 \mathrm{bp}$ \\
MDCOL2 R & CTC CAA CTA TG-3' & \\
& 5'-TGA TT TAT TAT \\
\hline C. jejuni=Campylobacter jejuni, C. coli=Campylobacter \\
Coli, PCR=Polymerase chain reaction
\end{tabular}

Table-2: Cycling conditions for the PCR assay.

\begin{tabular}{lccc}
\hline Step & Temperature & Time & Cycle \\
\hline Initial denaturation & $95^{\circ} \mathrm{C}$ & $10 \mathrm{~min}$ & \\
Denaturation & $95^{\circ} \mathrm{C}$ & $30 \mathrm{sec}$ & $35 \mathrm{cycles}$ \\
Primer annealing & $59^{\circ} \mathrm{C}$ & $60 \mathrm{sec}$ & \\
Extension & $72^{\circ} \mathrm{C}$ & $60 \mathrm{sec}$ & \\
Final extension & $72^{\circ} \mathrm{C}$ & $10 \mathrm{~min}$ & \\
\hline
\end{tabular}

$\mathrm{PCR}=$ Polymerase chain reaction

examination, out of which species wise prevalence was $24(60 \%)$ from dog, $27(71.05 \%)$ from poultry and $16(61.54 \%)$ from calves was recorded.

\section{Molecular identification of the isolates}

All the Campylobacter isolates recovered from conventional culture method was tested by PCR targeting mapA gene for $C$.jejuni and ceuE for C.coli. Out of the 67 Campylobacter isolates 6 isolates belong to $C$.jejuni species, were 5 $(18.51 \%)$ from poultry and $1(4.17 \%)$ from dog and 17 to C.coli species were $9(33.33 \%)$ from poultry, $6(25 \%)$ from dog and 1 from calves were identified as zoonotic thermophilic Campylobacter (Figures-1 and -2).

\section{Discussion}

Thermophilic Campylobacters are major foodborne pathogens of animal origin and leading cause of gastrointestinal infections. The importance of this disease is compounded by the fact that very low doses of Campylobacter in the food samples are capable of causing infections unlike other foodborne infection. In India, the prevalence of Campylobacter is underestimated which may be due to its way of cooking and food habit.

The advent of molecular biology techniques such as PCR has largely replaced the conventional isolation procedure by virtue of its speed, sensitivity and discriminating power. The conventional isolation procedure although time-consuming and cumbersome still remains the gold standard.

The finding of the present study is comparable with a report of Kassa et al. [13] were the prevalence of Campylobacter spp. in chickens observed was (68.1\%). In one study, the frequency of isolation of Campylobacter spp. in dogs varied from 17\% (Brazil, 


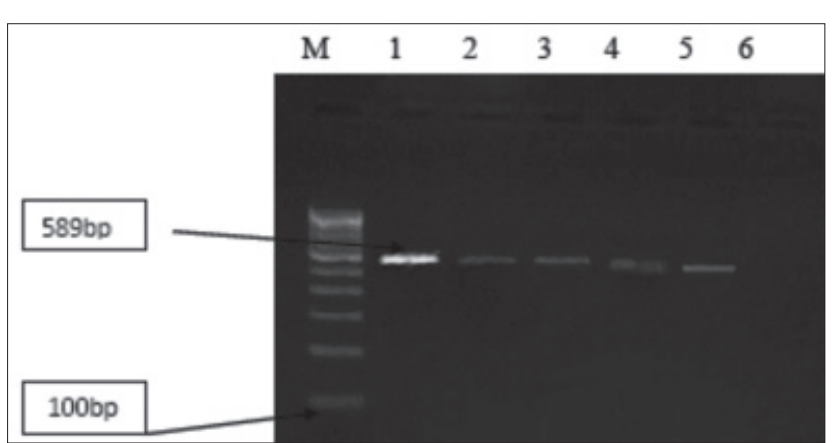

Figure-1: Agarose gel showing polymerase chain reaction amplified product at (589 bp) for mapA genes in Campylobacter isolates. M: Molecular marker (100 bp, Fermentas); Lane 1: Positive control; Lane 2-5: Positive samples; Lane 6: Negative control

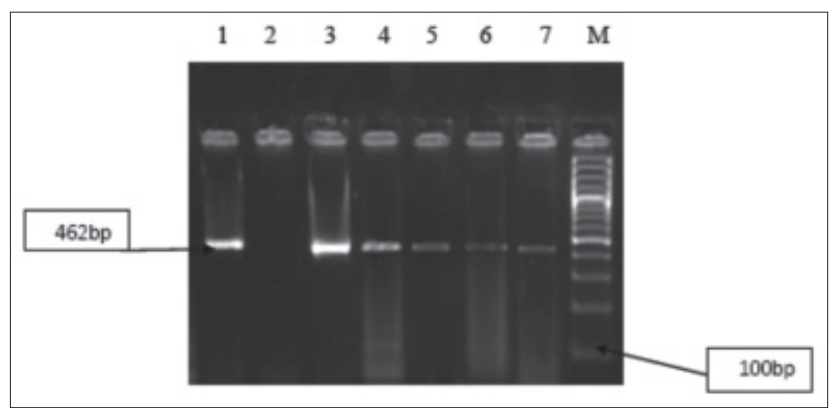

Figure-2: Agarose gel showing polymerase chain reaction amplified product at (462 bp) for ceu genes in Campylobacter isolates. Lane 1: Positive control; Lane 2: Negative control; Lane 3-7: Positive samples; M: Molecular marker (100 bp, Fermentas).

Argentina) to $76.2 \%$ (Denmark) [4,14]. However, there are several reports of higher isolation rates of Campylobacter from cattle, ranging from 5\% to $89.4 \%$ [15]. Workman et al. [16] also reported the prevalence of Campylobacter spp. from rectal swabs of dogs to be $46.9 \%$ and from cloacal swabs of broiler chicks $94.2 \%$. Amar et al. [17] reported the prevalence of Campylobacter in chicken flocks (33-44\%), cattle $(15 \%)$ and in healthy dogs $(6 \%)$ in Switzerland.

Molecular characterization of two different gene targets for $C$. jejuni and C. coli was attempted; the targeted gene was mapA and ceuE. In one study, Sandberg et al. [18] reported that about $7 \%$ of the isolates from dog were positive for C.coli and $6 \%$ for C.jejuni. A Dutch study reported the prevalence ranging from $20 \%$ to $31 \%$ in poultry were C. jejuni was $(5.38 \%)$ and C.coli $(2.3 \%)[19,20]$. Awadallah et al. [21] also reported C.coli $(7.4 \%)$ and C. jejuni(3.7\%) from chicken cloacal swabs.

Prevalence of Campylobacter varies between countries depending on the level of hygienic measures followed. This variation in getting a low number of isolates positive for mapA and ceuE gene may be due to the primers used, the prevalence of inhibitors, laboratory condition, seasonal variations as well as geographic diversity in the distribution of C.jejuni and C.coli isolates.

\section{Conclusion}

Our findings suggest that chicken, calves and pet dogs can play a role as the reservoir of potentially pathogenic Campylobacter strains for humans. Hence, proper public health protection measures should be taken to control it and prevent its transmission from the reservoir. PCR can be used an ideal tool for molecular confirmation at the species level.

\section{Author's Contributions}

MS and LG have designed the study project as well as corrected the manuscript, SB has done the research work, data compiling and manuscript preparation. $\mathrm{MG}, \mathrm{GS}, \mathrm{PASM}$, and $\mathrm{AK}$ helped in doing the research work. All authors read and approved the final manuscript.

\section{Acknowledgements}

The authors are thankful to the Department of Veterinary Public Health and Epidemiology, Madras Veterinary College, Chennai for the facilities provided for the completion of this research.

\section{Competing Interests}

The authors declare that they have no competing interests.

\section{References}

1. Chaban, B., Ngeleka, M. and Hill, J.E. (2010) Detection and quantification of 14 Campylobacter species in pet dogs reveals an increase in species richness in feces of diarrheic animals. BMC Microbiol., 10: 73 .

2. Zhao, S., Young, S.R., Tong, E., Abbott, J.W., Womack, N., Friedman, S.L. and McDermott, P.F. (2010) Antimicrobial resistance of Campylobacter isolates from retail meat in the United States between 2002 and 2007. Appl. Environ. Microbiol., 76: 7949-7956.

3. Scallan, E., Hoekstra, R.M., Angulo, F.J., Tauxe, R.V., Widdowson, M.A. and Roy, S.L. (2011) Food borne illness acquired in the United States major pathogens. Emerg. Infect. Dis., 17: 7-15.

4. Salihu, M.D., Magaji, A.A., Abdulkadir, J.U. and Kolawale, A. (2010) Survey of thermophilic Campylobacter species in cats and dogs in North-Western Nigeria. Vet. Ital., 46: 425-430.

5. Meerburg, B.G., Jacobs-Reitsma, W.F., Wagenaar, J.A. and Kijlstra, A. (2006) Presence of Salmonella and Campylobacter spp. in wild small mammals on organic farms. Appl. Environ. Microbiol., 72(1): 960-962.

6. Kittl, S., Heckel, G., Korczak, B.M. and Kuhnert, P. (2013) Source attribution of human Campylobacter isolates by MLST and Fla-Typing and association of genotypes with quinolone resistance. PLoS One,8(11): e81796.

7. Acke, E., Carroll, C., O’Leary, A., McGill, K., Kelly, L., Lawlor, A., Madden, R.H., Moran, L., Scates, P., McNamara, E., Moore, J.E., Jones, B.R., Fanning, S. and Whyte, P. (2011) Genotypic characterization and cluster analysis of Campylobacter jejuni isolates from domestic pets, human clinical cases and retail food. Iran. Vet. J., 64: 6.

8. Jokinen, C.C., Schreier, H., Mauro, W., Taboada, E., IsaacRenton, J.L., Topp, E., Edge, T.,Thomas, J.E. and Gannon, V.P.J. (2010) The occurrence and sources of Campylobacter spp., Salmonella enterica and Escherichia coli O157:H7 in the Salmon River, British Columbia, Canada. J. Water Health, 8: 374-386. 
9. Jokinen, C., Edge, T.A., Ho, S., Koning, W., Laing, C., Mauro, W., Medeiros, D., Miller, J., Robertson, W., Taboada, E., Thomas, J.E., Topp, E., Ziebell, K. and Gannon, V.P.J. (2011) Molecular subtypes of Campylobacter spp., Salmonella enterica, and Escherichia coli O157:H7 isolated from faecal and surface water samples in the Oldman river watershed, Alberta, Canada. Water Res., 45: 1247-1257.

10. Denis, M., Petton, J., Refregier-Laisney, M.J., Ermel, G. and Salvat, G. (2001) Campylobacter contamination in French chicken production from farm to consumers. Use of a PCR assay for detection and identification of Campylobacter jejuniand Campylobacter coli. J. Appl. Microbiol., 91: 255-67.

11. Melo, R.T., Nalevaiko, P.C., Mendonça, E.P., Borges, L.W., Fonseca, B.B., Beletti, M.E. and Rossi, D.A. (2013) Campylobacter jejuni strains isolated from chicken meat harbor several virulence factors and represent a potential risk to humans. Food Control, 33: 227-231.

12. Vaidyalingam, K. and Laxminarayan, C.S. (1980) Internal gas generator system suitable for creating anaerobiosis. Indian. J. Surg., 42: 154-9.

13. Tesfaye, K., Gebre-selassie, S. and Asrat, D. (2005) The prevalence of thermo tolerant Campylobacter species in food animals in Jimma Zone, southwest Ethiopia. Ethiop.J.Health Dev., 19(3):225-229.

14. Acke, E., McGill, K., Golden, O., Jones, B.R, Fanning, S. and Whyte, P. (2009) Prevalence of thermophilic Campylobacter species in household cats and dogs in
Ireland. Vet. Rec., 164: 44-47.

15. Hoar, B.R., Atwill, E.R., Elmi, C. and Farver, T.B. (2001) An examination of risk factors associated with beef cattle shedding pathogens of potential zoonotic concern. Epidemiol. Infect.,127:147-155.

16. Workman, S.N., Mathison, G.E. and Lavoie, M.C. (2005) Pet dogs and chicken meat as reservoirs of Campylobacter spp. in barbados. J.Clin. Microbiol., 43(6): 2642-2650.

17. Amar, C., Kittl, S., Spreng, D., Thomann, A., Korczak, B.M. and Burnens, A.P. (2013) Genotypes and antibiotic resistance of canine Campylobacter jejuni isolates. Vet. Microbiol., 168: 124-30.

18. Sandberg, M., Bergsjo, B., Hofshaga, M., Skjerve, E. and Kruse, H. (2002) Risk factors for Campylobacter infection in Norvegian cats and dogs. Prev. Vet. Med., 55: 241-253.

19. Van Asselt, E.D., Jacobs-Reitsma, W.F., Van Brakel, R., Van Der Voet, H. and Van Der Fels-Klerx, H.J. (2008) Campylobacter prevalence in the broiler supply chain in the Netherlands. Poultr. Sci., 87: 2166-2172.

20. Affar, N.A.M. (2009) Shedding and colonisation of Campylobacter coli in broilers from day of hatch to slaughter. Microbiology, Pp 60.

21. Awadallah, M.A.I., Ahmed, H.A., El-Gedawy, A.A. and Saad, A.M. (2014). Molecular identification of C. jejuni and C. coli in chicken and humans, at Zagazig, Egypt, with reference to the survival of $C$. jejuni in chicken meat at refrigeration and freezing temperatures. Int. Food Res. J., 21(5): 1801-1812. 